\title{
Employment Status and Intimate Partner Violence Among Mexican Women
}

Journal of Interpersonal Violence 2015, Vol. 30(7) II28-II52

(C) The Author(s) 2014

Reprints and permissions: sagepub.com/journalsPermissions.nav DOI: $10.1|77 / 08862605| 4539848$ jiv.sagepub.com @SAGE

\author{
Elizabeth C. Terrazas-Carrillo, MA' \\ and Paula T. McWhirter, PhD'
}

\begin{abstract}
Exploring risk factors and profiles of intimate partner violence in other countries provides information about whether existing theories of this phenomenon hold consistent in different cultural settings. This study will present results of a regression analysis involving domestic violence among Mexican women $(n=83,159)$. Significant predictors of domestic violence among Mexican women included age, number of children in the household, income, education, self-esteem, family history of abuse, and controlling behavior of the husband. Women's employment status was not a significant predictor when all variables were included in the model; however, when controlling behavior of the husband was withdrawn from the model, women's employment status was a significant predictor of domestic violence toward women. Results from this research indicate that spousal controlling behavior may serve as a mediator of the predictive relationship between women's employment status and domestic violence among Mexican women. Findings provide support for continued exploration of the factors that mediate experiences of domestic violence among women worldwide.
\end{abstract}

\section{Keywords}

domestic violence and cultural contexts, domestic violence, cultural contexts, predicting domestic violence

\footnotetext{
'University of Oklahoma, Norman, USA

Corresponding Author:

Elizabeth C. Terrazas-Carrillo, University of Oklahoma, 820 Van Vleet Oval, Rm. 32I,

Norman, OK, 73019-2014 USA.

Email: elizabeth.terrazas@ou.edu
} 
Intimate partner violence (IPV) is a worldwide social issue, and according to the recent World Health Organization (WHO) report, the population-based incidence of IPV ranges from $13 \%$ to $72 \%$ worldwide (Bott, Morrison, \& Ellsberg, 2005; García-Moreno, Jansen, Ellsberg, Heise, \& Watts, 2006). Across a variety of cultural settings, women are at higher risk of violence from an intimate partner than from any other type of perpetrator (GarcíaMoreno et al., 2006). Generally speaking, however, the WHO report found lower rates of IPV in industrialized countries. The WHO report also identified factors that protect or put women at risk of IPV, which at the individual level include education, financial autonomy, previous victimization, empowerment and social support, and a history of violence in her family of origin (WHO, 2005).

Research documenting the impact of education, financial autonomy, and empowerment has been the basis of interventions implemented in various countries around the world, including South Africa, Bangladesh, and India (Vyas \& Watt, 2009). However, the results of such interventions have been mixed. Some programs showed decreases in IPV resulting from increases in household income through the provision of microfinancing and loans to women (Vyas \& Watt, 2009). However, similar programs revealed an increase in IPV among the women benefiting from these lending programs (Dalal, 2011; Hindin \& Adair, 2003). Research including working and non-working women in developing countries has also yielded mixed results, with some working women deriving significant benefits from the resulting empowerment of employment and others experiencing an increase in their risk of violence by their partner (Dalal, 2011; Vyas \& Watt, 2009).

Theoretical formulations have been created to explain the impact of economic status and participation in the labor markets on IPV. Marital dependence theory suggests that employed women are less dependent on their husbands, and thus, less likely to tolerate abuse (Villarreal, 2007). Research conducted by Kalmuss and Straus (1990) found that women without viable alternative to marriages tend to be more tolerant of abuse, including physical abuse. Resource theory and the modified relative resource theory propose that violence is a means to balance power within a relationship (Villarreal, 2007). Proponents of this theory suggest that imbalanced access to resources relative to those of the other spouse may trigger the use of violence as a means to restore power superiority within a relationship (Atkinson, Greenstein, \& Lang, 2005; Villarreal, 2007). For example, research by McCloskey (1996) found that women with significantly higher incomes are at higher risk of abuse by their partners, and Macmillan and Gartner (1999) found that employed wives are more likely to be abused by unemployed husbands. However, Atkinson et al. (2005) posit that both resource theory and 
relative resource theory fail to account for cultural variables including the extent to which traditional gender roles are embraced. Gender ideologies, or how an individual identifies the self with regard to marital and family roles linked to gender, act as a moderator between the relationship of active participation in the labor force and IPV (Atkinson et al., 2005). This theory was coined gendered resource theory and has received some empirical support (Atkinson et al., 2005). Thus, the nature of the relationship between active labor participation and IPV is highly contextualized and varies across cultures. Therefore, examination of this relationship in other countries and cultural contexts is likely to yield knowledge about factors that protect or put women at risk of IPV around the world.

\section{Women's Economic Status and IPV}

Internationally, research has identified a breadth of social and psychological benefits generally associated with employment (e.g., Artazcoz, Borrell, Benach, Cortes, \& Rohlfs, 2004; Creed \& Macintyre, 2001; Kar, Pascual, \& Chickering, 1999); however, studies of women's economic enhancement and its impact on partner violence have yielded inconclusive results in the literature. Although some studies have documented a positive impact on women's status resulting from gainful employment, others have shown increases of IPV resulting from increased access to financial resources (Bott et al., 2005; Heise \& García-Moreno, 2002; Koenig, Ahmed, Hossain, \& Mozumder, 2003). For instance, Kim et al. (2007) report on the results of implementing an intervention program aimed to reduce the risk of HIV infection and increase gender equality. The program was called Intervention with Microfinance for AIDS and Gender Equity (IMAGE) and was built on the theory that combating poverty and women's subordinate status in South Africa would result in a decrease in HIV infection and IPV among women in this country. One of the main goals of the IMAGE program was women's empowerment and the researchers defined it as women's ability to support their family. As a result, the IMAGE program also included a microfinance component with the idea that providing credit to women will affect their ability to support their families. Evaluation of the impact of the program showed a reduction in the risk of IPV by more than half (initial estimates of IPV were about $71.3 \%$ among the women participating in the program). This program exemplifies the reduction in rates of IPV by providing women the means to gainful employment. Other programs have reported similar positive results (see Bhattacharyya, Bedi, \& Chhachhi, 2011; Blumberg, 1991; Costello, Chung, \& Carson, 2005; Hashemi, Schuler, \& Riley, 1996; Jewkes, 2002). 
Contradictory results have been found in other research studies (Dalal, 2011; Hindin \& Adair, 2003; Jejeebhoy, 1998; Koenig et al., 2003; Rahman, Hoque, \& Makinoda, 2011; Schuler, Hashemi, \& Badal, 1998). For example, a research report by Dalal (2011) concluded that economic empowerment by means of earning was not protective of IPV in India. Dalal (2011) found a higher prevalence of IPV in all forms of violence among working women. More detailed analysis revealed that Indian women who earned less than or the same income as their partners experienced less risk of IPV compared with those who made more money. In addition, Dalal found that unemployed husbands were more likely to abuse their wives compared with those making less money than their wives. This research suggests that working women with higher education had higher risk of IPV compared with their non-working peers in India. These results are congruent with those of Macmillan and Gartner (1999) using data from the Violence Against Women Survey in Canada.

Another example of such contradictory findings involves a Mexican welfare program. Angelucci (2008) found similar increases in exposure to IPV resulting from women's access to financial resources acquired through participating in Mexico's program Opportunidades (Opportunities), a federallevel welfare program aimed at helping poor families. The evaluation of this program found an increase in violence committed by husbands against wives. Specifically, Angelucci found that uneducated husbands were more likely to abuse their younger, also uneducated wives if their income supplement was higher than their earned income. Other studies have found similar effects of women's income earning increases in developing countries such as Bangladesh and the Philippines (see Hindir \& Adair, 2003; Jejeebhoy, 1998; Koenig et al., 2003; Krishnan et al., 2010; Rahman et al., 2011; Schuler et al., 1998; Schuler, Hashemi, Riley, \& Akhter, 1996).

In light of these research findings, theories have emerged explaining the differential impact of financial independence on women's empowerment and IPV. Jewkes (2002) emphasizes the importance of inequality in the context of poverty, as husbands may be more sensitive to inequity in income even when the absolute level of income increases. Moreover, the impact of masculine ideology seems to play a role in determining whether women's empowerment results in increased IPV. For men in some cultures, fulfilling their identity as males is closely tied to the ability to provide for their family (Jewkes, 2002; Macmillan \& Gartner, 1999; Maldonado, Nájera, \& Segovia, 2005). However, violence against women may have its origins in men's vulnerability. Jewkes (2002) reports that when social expectations of manhood are unattainable, men may choose to express masculine power that is otherwise denied through violence against women. In most cases, poor economic conditions may make the ideal of masculinity, as tied to the role of provider to 
the family, unattainable. In addition, female empowerment is usually defined in terms of education, income, and leadership roles. However, Jewkes refers to these components as not equally protective of IPV. In other words, having some education may empower women to challenge certain gender roles, but educated women may not have the financial resources to leave an abusive husband. Jewkes proposes that the highest risk of IPV is for women in the middle of the education continuum, where they may have exposure to more liberal ideas about gender roles but no real power to become independent within their societies. Heise and García-Moreno (2002) describe this model with the following statement: "Where women have a very low status, violence is not 'needed' to enforce male authority ... Partner violence is thus usually highest at the point where women begin to assume non-traditional roles or enter the workforce" (p. 99).

Bott et al. (2005) and Chronister and McWhirter (2006) advocate the need to adopt an ecological model in understanding the relationship between employment and IPV. Bott et al. report that similar conditions may have different meanings and effects on a woman's risk of IPV depending on the society's cultural norms regarding gender. Thus, they propose a model where not only individual or relationship factors are accounted for but also community and society values and norms are taken into account. Bott et al. and Heise and García-Moreno (2002) propose that increases in violence resulting from a woman's increase in earning power is a by-product of the cultural, societal, and community attitudes about gender roles.

\section{The Impact of Coercive Control on IPV}

Two major theories of IPV have emerged in the last century: the feminist theory of IPV and family violence theory. Feminist theory proposes that IPV is an expression of gender-based domination of women by men (Lawson, 2012). R. E. Dobash and Dobash (1979) pioneered the view of IPV as a gender issue, proposing that partner abuse is fundamentally based on male's need for domination. Their central argument is expressed in the preface of their book: "The use of physical violence against women in their position as wives is not the only means by which they are controlled and oppressed but it is one of the most brutal and explicit expressions of patriarchal domination" (R. E. Dobash \& Dobash, 1979, p. ix). However, family violence theorists see IPV as a method used by partners to resolve inevitable conflict within the family (Lawson, 2012; Straus \& Gelles, 1986). The overall view of family violence theory is that conflict is a part of society, and the family being a smaller societal unit is likely to experience conflict. Therefore, IPV is a form of violence used to solve family conflicts (Lawson, 2012). 
The debate between feminist theorists and family violence theorists intensified when results of the first national survey of IPV in the United States indicated that women were as likely to engage in violence as men (Straus, 1979; Straus \& Gelles, 1986, 1990). More recent studies using large random samples in the United States have found that IPV has gender symmetry, meaning women are as likely to commit acts of violence as men (Archer, 2000; Straus, 2005). Prominent feminist theorists responded by arguing that using the Conflict Tactics Scale (CTS) to measure IPV provides an unreliable and invalid picture of this social problem (R. E. Dobash \& Dobash, 1979, R.P. Dobash et al., 1992). R.P. Dobash et al. (1992) reported that the CTS ignores the underlying motives and meanings of violence, as well as the consequences for women. Methodologically, feminist analyses are more likely to be based on data collected from women using shelters, hospitals, or law enforcement assistance (Johnson, 1995; Lawson, 2012).

Johnson (1995) proposed a typology that distinguished between the violence reported by large random samples versus the violence reported by women utilizing services such as shelters and hospitals. Johnson (1995) proposed two types of violence: patriarchal terrorism (PT) and common couple violence (CCV). PT is defined as a pattern of domination and control of women. In this type of violence, coercive control acts acquire a "terroristic" character (Carney \& Barner, 2012; Johnson \& Leone, 2005). Tanha, Beck, Figueredo, and Raghavan (2010) describe coercive control as a pattern of violence, intimidation, isolation, where the individual seeks to restrict the victim's liberties. Specific characteristics of PT include higher frequency of violence that is usually initiated by the husband and likely to escalate over time, exercise of general control of the victim, and use of multiple control tactics (Johnson, 1995, 2006; Lawson, 2012; Leone, Johnson, Cohan, \& Lloyd, 2004). Research shows that this type of violence is gender asymmetric, with men being more likely to perpetrate violence against women (Johnson, 1995; Johnson \& Leone, 2005; Kelly \& Johnson, 2008). PT victims are more likely to use shelters and/or hospitals and tend to be underrepresented in large random surveys (Anderson, 2008; Leone, Johnson, \& Cohan, 2007). In addition, victims of PT are more likely to suffer from depression, severe injuries, miss work, and experience posttraumatic stress disorder (PTSD; Anderson, 2008; Frye, Manganello, Campbell, Walton-Moss, \& Wilt, 2006; GrahamKevan \& Archer, 2003; Johnson, 1995, 2006; Kelly \& Johnson, 2008).

Johnson (1995) identified CCV as resulting from a conflict that gets out of hand and leads to minor forms of violence. This type of violence is not the result of patriarchal domination, rarely escalates, and rarely results in severe injury to the victim (Carlson \& Jones, 2010; Johnson, 1995). CCV does not tend to be a pattern, but rather an intermittent response to occasional conflicts 
within the couple (Johnson, 1995, 2006). Further evidence has emerged indicating that $\mathrm{CCV}$ is the type of violence most likely measured by large random surveys and it shows gender symmetry because both men and women are likely to engage in CCV (Anderson, 2008; Carlson \& Jones, 2010; Carney \& Barner, 2012; Graham-Kevan \& Archer, 2003; Johnson, 1995, 2006). Leone et al. (2007) found that victims of CCV are less likely to seek out help in shelters or from law enforcement, and are likely to use informal sources of help, including family and friends. Johnson's (1995) typology seems to explain most of the differences between data available from shelter samples and large random samples. In addition, this typology may elucidate the impact of employment on IPV, as it is possible that a pattern of PT would be more likely to pervade all aspects of the relationship, including women's employment and its impact on the dominance of the husband.

\section{IPV in Mexico}

Although IPV has been studied in the United States for the last 30 years, the investigation of this public health issue in Mexico only began in the 1990s (Olaiz, Franco, et al., 2006; Olaiz, Rojas, et al., 2006). It was during this time that Mexico began studying IPV prevalence and developed initiatives to aid women involved in violent situations (Instituto Nacional de Estadística, Geografía e Informática, 2007). Estimates of prevalence rates of IPV among Mexican women have varied significantly, oscillating between $30 \%$ and $70 \%$ (Alvarado-Zaldívar, Salvador-Moysen, Estrada-Martínez, \& TerronesGonzález, 1998; Castro, Peek-Asa, \& Ruiz, 2003; Gómez-Dantes, VázquezMartínez, \& Fernández-Cantón, 2006; Olaiz, Franco, et al., 2006; Ramírez-Rodríguez \& Patiño-Guerra, 1996; Rivera-Rivera et al., 2004). These differences have been attributed to different conceptualizations of IPV across studies, use of different instruments, and use of localized geographical samples (Olaiz et al., 2006).

Due to the inconsistency of these estimates and the need to find out more about the factors influencing IPV among women in Mexico, the Instituto Nacional de Estadística, Geografía e Informática (INEGI) conducted the Encuesta Nacional sobre la Dinámica de las Relaciones en los Hogares (ENDIREH [National Survey on Household Relationship Dynamics]) in 2006. The survey was designed with the goal of identifying risk factors for IPV among women, therefore including measurements of socioeconomic status, relationship dynamics, gender role attitudes, and abusive behaviors (Instituto Nacional de Estadística, Geografía e Informática, 2007). Results from this survey indicated that an estimated $10.2 \%$ of Mexican females over the age of 15 who were married at the time of the survey reported violence by 
a partner in the last year (Instituto Nacional de Estadística, Geografía e Informática, 2007).

Research conducted in Western countries has provided a wealth of information about prevalence of IPV in developed countries, as well as risk factors predictive of violence against women (Holtzworth-Munroe, Bates, Smutzler, \& Sandin, 1997; Johnson \& Ferraro, 2000; Straus \& Gelles, 1986, 1990; Tjaden \& Thoennes, 2000a, 2000b; Villarreal, 2007). However, differences exist regarding the prevalence and risk factors for partner violence in developing countries. Johnson and Ferraro (2000) discussed the importance of remaining aware of ethnocentrism, or imposing Western ideas in understanding relationship dynamics in other cultures. Therefore, exploring risk factors and profiles of IPV in other countries provides information about whether existing theories of this phenomenon hold consistent in different cultural settings.

\section{Mexican Cultural Context}

Cross-cultural research studies have documented Latin Americans' emphasis on family's needs above the individual's (Flake \& Forste, 2006; Ingoldsby, 1991). According to Marin and Marin (1991), familismo values family relationships, reciprocity, loyalty, and solidarity. In this cultural context, children live at home until they are married and members of the nuclear and extended family socialize frequently and are expected to cooperate with each other. Familismo may act as a risk factor for Mexican women, as they are expected to sacrifice individual needs in pursuit of family unity and harmony. Although familismo seems to have a buffering effect against mental health issues among Latinos in the United States, its emphasis on loyalty and closeness with extended family members in the context of a patriarchal society can serve to enable partner abuse (Ayón, Marsiglia, \& Bermudez-Parsai, 2010; Flake \& Forste, 2006). In fact, Belknap (2010) found that young Mexican women seemed to hold ambivalent attitudes about valuing their autonomy while also acknowledging the centrality of the family in their lives. In Belknap's study, Mexican women appeared conflicted about whether to seek out independence or become the backbone of their family.

Another important cultural value relevant to the study of IPV refers to the Latino ideal of masculinity. Mexican men are considered the head of the household and main providers to the family (Weidel, Provencio-Vásquez, Watson, \& González-Guarda, 2008). While machismo encompasses a strong work ethic and responsibility, it is also characterized by extreme maleness and hypersexuality (Flake \& Forste, 2006; Weidel, et al., 2008). Machismo is consistent with the concept of hypermasculinity, which refers to men's tendency to engage in behaviors that assert physical power and dominance, 
often through the use of violence (Galanti, 2003; Mosher \& Sirkin, 1984; Vásquez Guerrero, 2009). Moreover, recent research found that men with high scores on a measure of hypermasculinity administered higher voltage shocks for longer periods of time to their female counterparts in a controlled experiment (Parrott \& Zeichner, 2003). Giraldo (1972) argues that machismo has its roots in the Spanish conquest, when Indian men were subjugated by the Spaniards. He further argues that in an effort to establish a level of superiority, men developed hypermasculine ideals that included subjugation of women (Giraldo, 1972). Ideals of machismo, however, are sustained by rigid adherence to gender roles by both men and women, and ecologically sustained by the sociopolitical structures in power in Mexico (Frias, 2010).

The opposite of machismo is the cultural value called marianismo, or the expectation that women should be self-sacrificing, chaste, and good mothers (Flake \& Forste, 2006; Heaton \& Forste, 2008; Weidel et al., 2008). Latino women are expected to pay deference to men and are expected to take care of their children and households (Flake \& Forste, 2006). Although some researchers have noted the change in Mexican gender roles by acknowledging that women seem to have some power in the private sphere of the family, they are indeed powerless at the structural level (Oropesa, 1997). In fact, a national survey conducted in 2003 by INEGI revealed that $12.4 \%$ of the women surveyed in a representative sample believed that their partner had the right to beat them if they did not fulfill their obligations as wives (Instituto Nacional de Estadística, Geografía e Informática, 2007). In a qualitative study of women in Chiapas, a southern state of Mexico, Ghantz and Halperin (1996) found that IPV is seen as normal, and as a method of discipline for failing to fulfill feminine roles. Agoff, Rajsbaum, and Herrera (2005) observed that Mexican women attributed partner violence to their trespassing of social norms regarding relationships, their manner of dressing, and availability to engage in sexual intercourse. In fact, women cited leaving their home without asking for permission, jealousy, defending their children, and bad housekeeping as reasons why their husbands would engage in partner violence (Alvarado-Zaldívar et al., 1998). Overall, these cultural values are relevant to understanding the context of IPV in Mexico. Understanding the cultural context can elucidate risk factors for women experiencing IPV in Mexico.

\section{Method}

\section{Sample}

Data for this study were collected for the ENDIREH in 2006 by the Mexican Instituto Nacional de Estadística, Geografía e Informática (INEGI), which is 
the government organization that carries out Mexico's decennial census. The sampling strategy used by the INEGI involved first creating a roster of all residents in a national probability sample of households in Mexico. As shown in Table 1, sampling included households within all 32 states throughout Mexico. In each of these households, one woman of 15 years of age or older currently living with a partner was selected at random from all residents in the same household meeting the aforementioned criteria. The interviews were carried out in person with the woman selected by trained INEGI workers. This data set included 83,159 women who were married or cohabited with a man at the time of the interview. A total $6.4 \%(5,281)$ of the women interviewed reported fluently speaking an indigenous language in addition to Spanish, and a total of $93.6 \%(77,829)$ of the women reported only speaking Spanish.

\section{Hypotheses}

It is hypothesized that woman's employment is not predictive of IPV when coercive control is accounted into the model. Therefore, coercive control is predicted to be a mediator variable linking woman's employment with a high likelihood of experiencing IPV.

\section{Measurement}

The ENDIREH consisted of a survey of questions covering a wide range of contexts where women may experience violence, including school, work, and the home. All women, married or unmarried living with a partner, answered a total of 684 questions on topics including characteristics of their homes, sociodemographic and eligibility questions, questions regarding women's experiences in school and work places, relationship dynamics, family of origin, tensions and conflicts, intimate partner abuse, decision and control in relationships, personal liberties, feminine and masculine role beliefs, and social capital.

Abuse scale. The key dependent variable in the analysis is the occurrence of physical violence against a woman by her husband or partner in the previous year. The ENDIREH asks a series of questions about specific abuse tactics to which the answer can be one time, several times, or never. A score was created for each participant by adding 1 point for every one time answer, 2 points for every several times answer, and 0 points for every never answer. In this manner, an index variable was created that reflects the frequency and intensity of the partner abuse, whereby higher scores indicate more frequent abuse 
Table I. Percentage of Mexican Women Interviewed per State.

\begin{tabular}{|c|c|}
\hline State & \% From Total (Total Women per State) \\
\hline Aguascalientes & $3.3(2,737)$ \\
\hline Baja California & $3.0(2,523)$ \\
\hline Baja California Sur & $2.9(2,449)$ \\
\hline Campeche & $3.2(2,626)$ \\
\hline Coahuila & $3.2(2,697)$ \\
\hline Colima & $2.9(2,447)$ \\
\hline Chiapas & $3.3(2,7 \mid 4)$ \\
\hline Chihuahua & $3.0(2,503)$ \\
\hline Distrito Federal & $2.9(2,390)$ \\
\hline Durango & $3.0(2,531)$ \\
\hline Guanajuato & $3.4(2,859)$ \\
\hline Guerrero & $3.1(2,544)$ \\
\hline Hidalgo & $2.0(2,424)$ \\
\hline Jalisco & $3.2(2,654)$ \\
\hline Estado de Mexico & $3.3(2,746)$ \\
\hline Michoacan & $3.1(2,576)$ \\
\hline Morelos & $2.9(2,437)$ \\
\hline Nayarit & $3.0(2,528)$ \\
\hline Nuevo Leon & $3.3(2,742)$ \\
\hline Oaxaca & $3.1(2,574)$ \\
\hline Puebla & $3.2(2,655)$ \\
\hline Queretaro & $3.2(2,646)$ \\
\hline Quitana Roo & $2.9(2,404)$ \\
\hline San Luis Potosi & $3.2(2,665)$ \\
\hline Sinaloa & $3.2(2,663)$ \\
\hline Sonora & $3.1(2,569)$ \\
\hline Tabasco & $3.1(2,54 I)$ \\
\hline Tamaulipas & $3.1(2,579)$ \\
\hline Tlaxcala & $3.4(2,866)$ \\
\hline Veracruz & $2.9(2,439)$ \\
\hline Yucatan & $3.2(2,691)$ \\
\hline Zacatecas & $3.3(2,740)$ \\
\hline Total & $100(83,159)$ \\
\hline
\end{tabular}

and engagement in more than one form of abuse (e.g., physical, emotional, sexual). The index variable for abuse was obtained from answers to the items listed in Table 2, such as, "In the past 12 months has your partner pushed you or pulled your hair? Threatened to leave you, hurt you, take your children or 
Table 2. Abuse Scale Questions.

In the past 12 months, has your partner ...

Pushed you or pulled your hair?

Tied you up?

Kicked you?

Thrown an object at you?

Beaten you with his hands or an object?

Tried to choke you or suffocate you?

Hurt you with a knife?

Fired a weapon on you?

Shamed you, or humiliated you?

Ignored you and not taking you into consideration or given you love?

Told you that you are cheating on him?

Made you feel fearful?

Threatened to leave you, hurt you, take your children or kick you out of your home?

Kept you at home and prohibited you to leave or receive visits?

Turned your children against you?

Stalked you, or spied on you?

Threatened to kill you, kill himself, or kill your children?

Destroyed, thrown away, or hidden your things away?

Stopped talking to you?

Been mad because the housekeeping is not done, the food is not to his liking, or thinks you did not do your chores?

Disagreed about how you spend money?

Not given you money for home expenses, even if he has money?

Not given you money to pay bills or has threatened not to give you money for bills?

Spent the money you need to pay bills?

Taken over your money or property?

Forbidden you to work or study?

Made you engage in sexual intercourse even if you do not want to?

Made you do things you do not like when you have sexual intercourse?

Used physical force to make you have sexual intercourse?

Note. Questions translated from the Spanish version of the ENDIREH questionnaire.

ENDIREH = Encuesta Nacional sobre la Dinámica de las Relaciones en los Hogares.

kick you out of your home? Kept you at home and prohibited you to leave or receive visits? Has forbidden you to work or study? Made you engage in sexual intercourse even if you do not want to?" The Cronbach's alpha coefficient for this variable is .913. 
Table 3. Coercive Control Scale Questions.

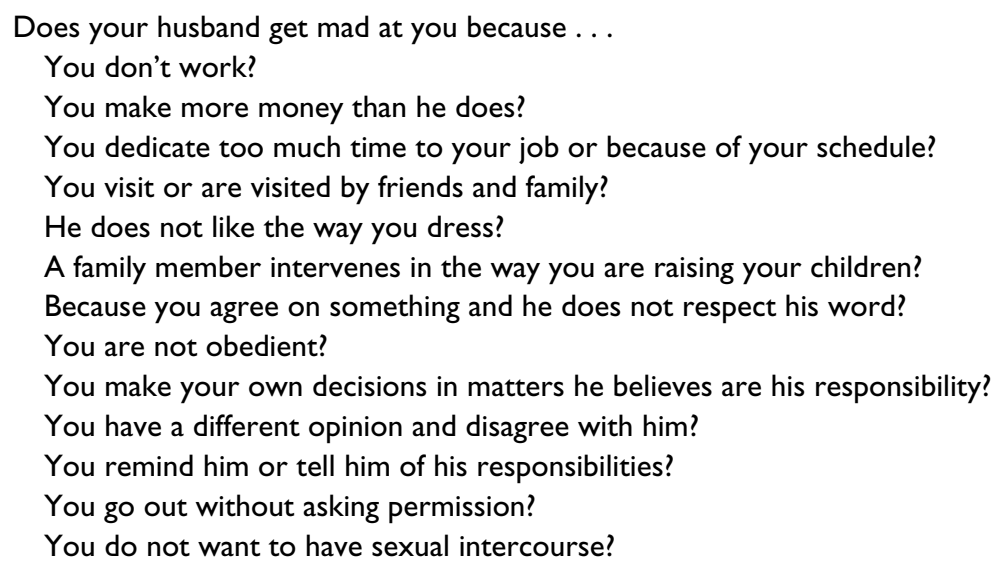

Note. Questions translated from the Spanish version of the ENDIREH questionnaire. ENDIREH = Encuesta Nacional sobre la Dinámica de las Relaciones en los Hogares.

Employment status. The ENDIREH asks both the male and female partners whether they work. Affirmative answers to the question of "Do you currently work?" for both partners were coded as " 1 " and negative answers were coded as " 0. ."

Coercive control scale. This variable was created by adding 1 point for each affirmative answer to questions listed in Table 3, which includes items such as, "Does your husband get mad at you because . . . You don't work? You make more money than he does? You visit or are visited by friends and family? He does not like the way you dress?" Higher values reflect a more pervasive level of control over a woman's life and choices. Cronbach's alpha for this variable is .80 .

Socioeconomic status. The ENDIREH provides information on both the male and female income in pesos. It also provides information on the level of education, which is measured as a continuous variable with 0 indicating no education and 10 indicating having a doctorate degree.

Family size. This variable was measured by answering the question, "In total, how many sons and daughters have you birthed?" A second question asks, "How many sons and daughters does your husband or partner have with other 
Table 4. Gender Role Index.

Does a good wife have to obey her husband in everything he orders?

Can a woman choose her friends even if her husband does not like them?

Does the man have to take responsibility for all expenses incurred by the family?

Is it a woman's duty to have sexual intercourse with her husband even if she does not want to?

Does the husband have the right to beat his wife if she does not comply with her duties?

Does a woman have the same ability as a man to earn money?

Do you agree that men and women should have the same rights to make their own decisions?

Do you agree that men and women should have the same freedoms?

Do you agree that women have the right to defend themselves and denounce any physical harm or aggression?

Do you agree that women have the chance to decide over their own life?

Do you agree that women have the right to live a life free of violence?

Note. Questions translated from the Spanish version of the ENDIREH questionnaire.

ENDIREH = Encuesta Nacional sobre la Dinámica de las Relaciones en los Hogares.

women?" Both variables indicate family size, as well as family structure and its potential impact on the primary dependent variable.

History of domestic violence. ENDIREH asks the following questions: "Do you remember if the people with whom you lived until you were 13 insulted or offended each other? Do you remember if the people with whom you lived until you were 13 years old beat each other?" The former indicates a history of emotional abuse, and the latter a history of physical abuse. An affirmative answer to each question was coded as " 1 " whereas a negative answer to the question was coded " 0. ."

Gender role index. This variable was created by adding 1 point for each affirmative answer to questions such as, "Does a good wife has to obey her husband in everything he orders? Can a woman choose her friends even if her husband does not like them?"

Similarly, 1 point was added when questions such as the following were answered negatively: "Does a woman have the same ability as a man to earn money? Do you agree that men and women should have the same rights to make their own decisions?" See Table 4 for the complete list of items. Higher values indicate a more conservative and traditional stance regarding gender role ideologies. Cronbach's alpha for this variable is .67. 
Table 5. Descriptive Statistics.

\begin{tabular}{lcc}
\hline Predictor & $M$ & $S D$ \\
\hline Age & 34.21 & 15.7 \\
Education & 3.5 & 1.633 \\
Woman's employment status & 0.36 & 0.479 \\
Husband's employment status & 0.88 & 0.319 \\
Salary of the husband or partner (in pesos) & $\$ 12,692.00$ & $83,536.28$ \\
Total children birthed & 3.26 & 2.38 \\
Total children husband had with other women & 0.38 & 1.379 \\
History of physical abuse & 2.58 & 0.747 \\
History of emotional abuse & 2.47 & 0.814 \\
Gender role attitudes & 2.24 & 1.47 \\
Abuse scale & 2.22 & 4.08 \\
Coercive control & 1.38 & 2.15 \\
\hline
\end{tabular}

\section{Results}

As detailed in Table 5, the mean age of women interviewed in this survey is 34.21 years. The mean education for women is 3.5 , that is, between middle school and high school. Women's employment status was measured as a dichotomous variable; therefore, a mean of 0.36 represents $36 \%$ of women who work outside the home. Similarly, husband or partner's employment status mean of 0.88 represents $88 \%$ of intimate partners who were employed at the time of the survey. The mean monthly salary for the employed male partner is $\$ 12,692$ pesos. Women on average bore 3.26 children, and husbands had an average of 0.38 children with other women. The mean average responses to the question assessing history of physical abuse is 2.58 (minimum $=1$, maximum $=3$ ) and history of emotional abuse is 2.47 (minimum $=$ 1 , maximum $=3$ ). The mean for the variable measuring gender role attitudes is 2.24 (minimum $=0$, maximum $=11$ ), with higher values on this scale describing endorsement of more traditional gender role attitudes and vice versa. The mean for the variable assessing abuse is 2.22 (minimum $=0$, maximum $=30$ ), indicating an overall low rate of IPV in this sample. The coercive control mean for this sample is 1.38 (minimum $=1$, maximum $=13$ ), showing low average levels of control in this sample.

The first model, detailed in Table 6, does not include the predictor coercive control and it has a $R^{2}$ of .27 , which means $23.7 \%$ of the variance in IPV is explained by the predictors gender role scale, husband's salary, number of children the husband has with other women, number of children birthed by the woman, age, husband's employment status, and history of emotional and 
Table 6. Multiple Regression Model.

\begin{tabular}{|c|c|c|c|}
\hline & $\beta$ & $B$ & $S E$ \\
\hline \multicolumn{4}{|l|}{ Model I } \\
\hline Age & $0.005^{*}$ & 0.043 & 0.001 \\
\hline Education & $0.108 *$ & 0.09 & 0.01 \\
\hline Woman's employment status & $1.185^{*}$ & 0.245 & 0.04 \\
\hline Husband's employment status & $1.185^{*}$ & 0.245 & 0.04 \\
\hline Salary of the husband or partner & -0.00063871 & -0.001 & 0 \\
\hline Total children birthed & $0.149 *$ & 0.14 & 0.001 \\
\hline $\begin{array}{l}\text { Total children husband had with } \\
\text { other women }\end{array}$ & $0.14^{*}$ & 0.074 & 0.001 \\
\hline History of physical abuse & $-0.062 *$ & -0.036 & 24 \\
\hline History of emotional abuse & $-0.285^{*}$ & -0.16 & 0.023 \\
\hline Gender role attitudes & $0.227^{*}$ & 0.13 & 0.011 \\
\hline \multicolumn{4}{|l|}{ Model 2} \\
\hline Age & $0.003 *$ & 0.028 & 0.001 \\
\hline Education & $0.023 *$ & 0.019 & 0.008 \\
\hline Woman's employment status & 0.046 & 0.006 & 0.027 \\
\hline Husband's employment status & $0.229 *$ & 0.047 & 0.031 \\
\hline Salary of the husband or partner & -0.00000001102 & 0 & 0 \\
\hline Total children birthed & $0.092^{*}$ & 0.086 & 0.005 \\
\hline $\begin{array}{l}\text { Total children husband had with } \\
\text { other women }\end{array}$ & $0.008 *$ & 0.039 & 0.001 \\
\hline History of physical abuse & $-0.108 *$ & -0.063 & 0.019 \\
\hline History of emotional abuse & $-0.073^{*}$ & -0.041 & 0.018 \\
\hline Gender role attitudes & $0.099 *$ & 0.057 & 0.009 \\
\hline Coercive control & $1.194 *$ & 0.657 & 0.006 \\
\hline
\end{tabular}

Note. $R^{2}=.237$ for Model I; $R^{2}=.54 \mathrm{I}$ for Model 2. $*$ indicates $p<.05$

physical abuse. The adjusted $R^{2}$ is also .237 , which indicates good crossvalidity of the model. The model is statistically significant, $F(10,60432)=$ $1881.05, p<.001$. All predictors except salary of the husband were statistically significant in the model.

The second model includes the predictor coercive control scale and it had a $R^{2}$ of .541 , which means that $54.1 \%$ of the variance in IPV in this model is explained by the following predictors: coercive control, salary of the husband, number of children husband has with other women, number of children birthed, age, gender role attitudes, husband's employment status, education, and emotional and physical abuse. The adjusted $R^{2}$ is also .541 indicating good cross-validity of the model. The model is statistically significant, $F(11$, 
$60442)=6466.82, p<.001$. The following predictors of IPV in the model are statistically significant: age, education, husband's employment status, number of birthed children, number of children husband has with other women, history of emotional and physical abuse, gender role attitudes, and coercive control. It is important to note that a woman's employment status is not a significant predictor in this model once coercive control is added to the model. Moreover, this model improved its goodness of fit by $30.4 \%$ by introducing the variable coercive.

\section{Discussion}

This study's findings contribute to our understanding of international research exploring the effects of women's employment. Inconsistent findings have emerged from research exploring the impact of providing microfinancing and loans to women in developing countries. For instance, some microlending programs show decreases in IPV resulting from increases in household income through the provision of microfinancing and loans to women while outcome studies of similar programs have revealed an increase in IPV among the women benefiting from enhanced economic power (Bhattacharyya et al., 2011; Blumberg, 1991; Costello et al., 2005; Hashemi et al., 1996; Jewkes, 2002; Koenig et al., 2003; Schuler et al., 1996; Vyas \& Watt, 2009). Research with working and non-working women in the developing world has also found mixed results; some working women derived significant benefits from the resulting empowerment of employment and others experienced an increase in their risk of violence by their partner (Dalal, 2011; Koenig et al., 2003; Krishnan et al., 2010; Rahman et al., 2011; Schuler et al., 1998; Vyas \& Watt, 2009).

Placing the study's findings in the context of other international studies, we speculate that increasing economic independence decreases IPV risk among women involved in relationships in which the spouse exhibits less controlling behavior. As such, involvement in the workforce may provide a preventive protective factor for women not yet exposed to IPV. However, the study's findings also reveal that increasing financial independence may increase vulnerability among women already experiencing insidious, relationally aggressive forms of IPV, such as spousal controlling behaviors. Researchers have hypothesized that the relationship between IPV and a woman's employment status is complex and embedded within the multiple contexts of her life, including individual factors, the influence of family, peer groups, culture, and local and global economic conditions (Chronister \& McWhirter, 2006). This study underscores the importance of adopting an ecological framework to understanding women's experience of IPV. Mexican 
women in less violent relationships may be more likely to benefit from working outside the home because it can potentially lead to social change by showing their husbands the benefits of earning added income. However, engaging in paid employment may be contraindicated for women in more vulnerable situations, specifically women subject to controlling husbands. These women would likely benefit from access to shelters and health resources as well as mental health interventions targeting the long-lasting effects associated with living in abusive relationships (Terrazas-Carrillo \& McWhirter, 2012). National and international policies regarding support of women's employment should be cognizant of these qualitative differences and provide supports that adequately meet women's needs rather than a blanket set of policies treating IPV as a monolithic phenomenon (McWhirter \& Altshuler-Bard, 2010; Vyas \& Watt, 2009).

Based on these findings, it is recommended that programs designed to increase women's financial stability should integrate both financial and personal empowerment. For instance, programs designed to improve women's financial quality of life should incorporate an understanding and awareness of personal and interpersonal knowledge, skills, and attitudes (Chronister \& McWhirter, 2006; McWhirter, 2006, 2007). Due to the realities of IPV internationally, interpersonal growth and development could be provided to women at a level commensurate with the financial training and support already being offered. Furthermore, paid work positions may be inaccessible to women in various regions internationally, particularly within rural communities. Therefore, other forms of economic activity might be considered within program development and implementation. For example, the IMAGE program implemented in South Africa targeted not only economic empowerment for women but also community growth initiatives such as having women support groups, and short-term classes targeting interpersonal development for men in the villages receiving microfinancing (Kim et al., 2007).

As previously mentioned, data for this study were collected by ENDIREH to inform initiatives within Mexico to aid women involved in violent situations. The Instituto Nacional de las Mujeres (National Institute of Women) in Mexico is the main entity in charge of promoting IPV prevention, information, and resources (Instituto Nacional de Estadística, Geografía e Informática, 2007). Results from this research suggest that counseling regarding career planning and intervention with women in more egalitarian relationships would function as a significant preventive effort against IPV. Encouraging these women to join the workforce may also translate in social change through a change in expectations from their partners (Vyas \& Watt, 2009). However, more intensive services and resources would be required for women in vulnerable, more violent relationships, where men assert control 
over not only their ability to work but also their contact with families, friends, and personal choices. For these women, access to short-term resources like shelters, and government assistance should be given priority. In addition, women should be provided access to counseling focused on the sequelae of abusive relationships, including PTSD, depression, anxiety, low self-esteem, and low self-efficacy, issues which in turn affect a woman's ability to find and sustain employment (McWhirter \& Altshuler-Bard, 2010).

As discussed in the introduction, men in some cultures strongly link their identity and worth to their ability to provide for their family (Jewkes, 2002; Macmillan \& Gartner, 1999; Maldonado et al., 2005). Findings from this study lend additional support to the salience of this issue for Mexican families. Based on findings of this study, interventions that enhance women's financial independence should be accompanied by interventions to target the effect of independence on the family. This should include a focus on educating women and men on the meaning of healthy relationships, and extending men's perception of identity and value beyond their ability to provide for their family (Ayón et al., 2010; Flake \& Forste, 2006; Ingoldsby, 1991).

\section{Declaration of Conflicting Interests}

The author(s) declared no potential conflicts of interest with respect to the research, authorship, and/or publication of this article.

\section{Funding}

The author(s) received no financial support for the research, authorship, and/or publication of this article.

\section{References}

Agoff, C., Rajsbaum, A., \& Herrera, C. (2005). Perspectivas de las mujeres maltratadas sobre la violencia de pareja en México [Perspectives from mistreated women about partner violence in Mexico]. Salud Pública de México, 48, S307-S314.

Alvarado-Zaldívar, G., Salvador-Moysen, J., Estrada-Martínez, S., \& TerronesGonzález, A. (1998). Prevalencia de violencia doméstica en la ciudad de Durango [Domestic violence prevalence in the city of Durango]. Salud Pública de México, 40, 481-486.

Anderson, K. L. (2008). Is partner violence worse in the context of control? Journal of Marriage and Family, 70, 1157-1168.

Angelucci, M. (2008). Love on the rocks: Domestic violence and alcohol abuse in rural Mexico. B. E. Journal of Economic Analysis \& Policy, 8, 1-41.

Archer, J. (2000). Sex differences in aggression between heterosexual partners: A meta-analytic review. Psychological Bulletin, 126, 651-680. 
Artazcoz, L., Borrell, C., Benach, J., Cortes, I., \& Rohlfs, I. (2004). Women, family demands, and health: The importance of employment status and socio-economic position. Social Science and Medicine, 59, 263-274.

Atkinson, M. P., Greenstein, T. N., \& Lang, M. M. (2005). For women, breadwinning can be dangerous: Gendered resource theory and wife abuse. Journal of Marriage and Family, 67, 1137-1148.

Ayón, C., Marsiglia, F. F., \& Bermudez-Parsai, M. (2010). Latino family mental health: Exploring the role of discrimination and familismo. Journal of Community Psychology, 38, 742-756.

Belknap, R. A. (2010). As time goes by we improve a little more: Relationship expectations of young women in Mexico. Health Care for Women International, 31, 873-890.

Bhattacharyya, M., Bedi, A. S., \& Chhachhi, A. (2011). Marital violence and women's employment and property status: Evidence from North Indian Villages. World Development, 39, 1676-1689.

Blumberg, R. L. (1991). Income under female vs. male control: Hypothesis from a theory of gender stratification and data from the Third World. In R. L. Blumberg (Ed.), Gender, family, and economy: The triple overlap (pp. 97-127). Newbury Park, CA: SAGE.

Bott, S., Morrison, A., \& Ellsberg, M. (2005). Preventing and responding to gender-based violence in middle and low-income countries: A global review and analysis (World Bank Policy Research Working Paper 3618). The World Bank: Washington, D.C.

Carlson, R. G., \& Jones, K. D. (2010). Continuum of conflict and control: A conceptualization of intimate violence typologies. Family Journal: Counseling and Therapy for Couples and Families, 18, 248-254.

Carney, M. M., \& Barner, J. R. (2012). Prevalence of partner abuse: Rates of emotional abuse and control. Partner Abuse, 3, 286-333.

Castro, R., Peek-Asa, C., \& Ruiz, A. (2003). Violence against women in Mexico: A study of abuse before and during pregnancy. American Journal of Public Health, 93, 1110-1116.

Chronister, K. M., \& McWhirter, E. H. (2006). An experimental examination of two career interventions for battered women. Journal of Counseling Psychology, 53, 151-164.

Costello, M., Chung, D., \& Carson, E. (2005). Exploring alternative pathways out of poverty: Making connections between domestic violence and employment practices. Australian Journal of Social Issues, 40, 253-267.

Creed, P.A., \& Macintyre, S.R. (2001). The relative effects of deprivation of the latent and manifest benefits of employment on the wellbeing of unemployed people. Journal of Occupational Health Psychology, 6, 324-331.

Dalal, K. (2011). Does economic empowerment protect women from intimate partner violence? Journal of Injury \& Violence Research, 3, 35-44.

Dobash, R. E., \& Dobash, R. P. (1979). Violence against wives: A case against the patriarchy. New York, NY: Free Press. 
Dobash, R. P., Dobash, R. E., Wilson, M., \& Daly, M. (1992). The myth of sexual symmetry in marital violence. Social Problems, 39, 71-91.

Flake, D. F., \& Forste, R. (2006). Fighting families: Family characteristics associated with domestic violence in five Latin American countries. Journal of Family Violence, 21, 19-29.

Frias, S. M. (2010). Resisting patriarchy within the state: Advocacy and family violence in Mexico. Women's Studies International Forum, 33, 542-551.

Frye, V., Manganello, J., Campbell, J. C., Walton-Moss, B., \& Wilt, S. (2006). The distribution of factors associated with intimate terrorism and situational couple violence among a population-based sample of urban women in the United States. Journal of Interpersonal Violence, 21, 1286-1313.

Galanti, G. (2003). The Hispanic family and male-female relationships: An overview. Journal of Transcultural Nursing, 14, 180-185.

García-Moreno, C., Jansen, H., Ellsberg, M., Heise, L., \& Watts, C. (2006). Prevalence of intimate partner violence: Findings from the WHO multi-country study on women's health and domestic violence. Lancet, 368, 1260-1269.

Ghantz, M., \& Halperin, D. C. (1996). Studying domestic violence: Perceptions of women in Chiapas, Mexico. Reproductive Health Matters, 4, 122-128.

Giraldo, O. (1972). El machismo como fenómeno psicocultural [Machismo as a psychocultural phenomenon]. Revista Latinoamericana de Psicología, 4, 295-309.

Gómez-Dantes, H., Vázquez-Martínez, J. L., \& Fernández-Cantón, S. B. (2006). La violencia en las mujeres usuarias de los servicios de salud en el Instituto Mexicano del Seguro Social y Servicios de Seguridad Social [Violence among women users of health services at the Mexican Institute of Social Security and Social Safety Services]. Salud Pública de México, 48, S279-S287.

Graham-Kevan, N., \& Archer, J. (2003). Intimate terrorism and common couple violence: A test of Johnson's predictions in four British samples. Journal of Interpersonal Violence, 18, 1247-1270.

Hashemi, S. M., Schuler, S. R., \& Riley, A. P. (1996). Rural credit programs and women's empowerment in Bangladesh. World Development, 24, 635-653.

Heaton, T. B., \& Forste, R. (2008). Domestic violence, couple interaction, and children's health in Latin America. Journal of Family Violence, 23, 183-193.

Heise, L., \& García-Moreno, C. (2002). Violence by intimate partners. In E. Knug, L. Dahlberg, J. A. Mercy, A. B. Zwi, \& R. Lozano (Eds.), World report on violence and health (pp. 87-113). Geneva, Switzerland: World Health Organization.

Hindin, M. J., \& Adair, L. S. (2002). Who's at risk? Factors associated with intimate partner violence in the Philippines. Social Science \& Medicine, 55, 1385-1399.

Holtzworth-Munroe, A., Bates, L., Smutzler, N., \& Sandin, E. (1997). A brief review of the research on husband violence. Aggression and Violent Behavior, 2, 65-99.

Ingoldsby, B. B. (1991). The Latin American family: Familism vs. machismo. Journal of Comparative Family Studies, 22, 57-62.

Instituto Nacional de Estadística, Geografía e Informática. (2007). Encuesta Nacional sobre la Dinámica de las Relaciones en los Hogares 2006: Marco Conceptual. [National Survey on Household Relationship Dynamics 2006: Conceptual Framework] Aguascalientes, México: Author. 
Jejeebhoy, S. J. (1998). Associations between wife-beating and fetal and infant death: Impressions from a survey in rural India. Studies in Family Planning, 29, 300308.

Jewkes, R. (2002). Intimate partner violence: Causes and prevention. The Lancet, $359,1423-1429$.

Johnson, M. P. (1995). Patriarchal terrorism and common couple violence: Two forms of violence against women. Journal of Marriage and the Family, 57, 283-294.

Johnson, M. P. (2006). Conflict and control: Gender symmetry and asymmetry in domestic violence. Violence Against Women, 12, 1003-1018.

Johnson, M. P., \& Ferraro, K. J. (2000). Research on domestic violence in the 1990s: Making distinctions. Journal of Marriage and the Family, 62, 948-963.

Johnson, M. P., \& Leone, J. M. (2005). The differential effects of intimate terrorism and situational couple violence: Findings from the National Violence Against Women Survey. Journal of Family Issues, 26, 322-349.

Kalmuss, D. S., \& Straus, M. A. (1990). Wife's marital dependency and wife abuse. In M. A. Straus \& R. J. Gelles (Eds.), Physical violence in American families: Risk factors and adaptations to violence in 8,145 families (pp. 113-132). New Brunswick, NJ: Transaction.

Kar, S.B., Pascual, C.A., \& Chickering, K.L. (1999). Empowerment of women for health promotion: A meta-analysis. Social Science \& Medicine, 49, 1431-1460.

Kelly, J. B., \& Johnson, M. P. (2008). Differentiation among types of intimate partner violence: Research update and implications for interventions. Family Court Review, 46, 476-499.

Kim, J. C., Watts, C., Hargreaves, J. R., Ndhlovu, J. X., Godfrey, P., Morison, L. A., \& Pronyk, P. (2007). Understanding the impact of a microfinance-based intervention on women's empowerment and the reduction of intimate partner violence in South Africa. American Journal of Public Health, 97, 1794-1802.

Krishnan, S., Rocca, C.H., Hubbard, A.E., Subbiah, K., Edmeades, J., \& Padian, N.S. (2010). Do changes in spousal employment status lead to domestic violence? Insights from a prospective study in Bangalore, India. Social Science \& Medicine, 70, 136-143.

Koenig, M. A., Ahmed, S., Hossain, M. B., \& Mozumder, K. A. (2003). Women's status and domestic violence in rural Bangladesh: Individual and community-level effects. Demography, 40, 269-288.

Lawson, J. (2012). Sociological theories of intimate partner violence. Journal of Human Behavior in the Social Environment, 22, 572-590.

Leone, J. M., Johnson, M. P., \& Cohan, C. L. (2007). Victim help seeking: Differences between intimate terrorism and situational couple violence. Family Relations, 56, 427-439.

Leone, J. M., Johnson, M. P., Cohan, C. L., \& Lloyd, S. E. (2004). Consequences of male partner violence for low-income minority women. Journal of Marriage and Family, 66, 474-490.

Macmillan, R., \& Gartner, R. (1999). When she brings home the bacon: Laborforce participation and the risk of spousal violence against women. Journal of Marriage and the Family, 61, 947-958. 
Maldonado, I., Nájera, M., \& Segovia, A. (2005). Efectos del programa Oportunidades en las relaciones de pareja $y$ familiares [Effects of the Opportunities program in couple and family relationships]. Ciudad de México, DF: Colegio de México.

Marin, G., \& Marin, B.V. (1991). Research with Hispanic populations. Newbury Park, CA: Sage.

McCloskey, L. (1996). Socioeconomic and coercive power within the family. Gender \& Society, 10, 449-463.

McWhirter, P. T. (2006). Community therapeutic intervention for women healing from trauma. Journal for Specialists in Group Work, 31, 339-351.

McWhirter, P. T. (2007). Domestic violence and chemical dependency co-morbidity: Promoting eclectic responses to concomitant mental health concerns. International Journal of Mental Health Promotion, 9, 34-42.

McWhirter, P. T., \& Altshuler-Bard, E. (2010). International perspectives on domestic violence. In J. M. Lampinen \& K. Sexton-Radek (Eds.), Protecting children from violence (pp. 291-314). New York, NY: Psychology Press.

Mosher, D. L., \& Sirkin, M. (1984). Measuring a macho personality constellation. Journal of Research in Personality, 18, 150-163.

Olaiz, G., Franco, A., Palma, O., Echarri, C., Valdéz, R., \& Herrera, C. (2006). Diseño metodológico de la Encuesta Nacional sobre Violencia contra las Mujeres en México [Methodological design of the National Survey on Violence against Women in Mexico]. Salud Pública de México, 48, 328-335.

Olaiz, G., Rojas, R., Valdez, R., Franco, A., \& Palma, O. (2006). Prevalencia de diferentes tipos de violencia en usuarias del sector salud en México [Prevalence of different types of violence among women users of the health sector in Mexico]. Salud Pública de México, 48, S232-S238.

Oropesa, R. S. (1997). Development and marital power in Mexico. Social Forces, 75 , 1291-1317.

Parrott, D. J., \& Zeichner, A. (2003). Effects of hypermasculinity on physical aggression against women. Psychology of Men \& Masculinity, 4, 70-78.

Rahman, M., Hoque, A., \& Makinoda, S. (2011). Intimate partner violence against women: Is women empowerment a reducing factor? A study from a national Bangladeshi sample. Journal of Family Violence, 26, 411-420.

Ramírez-Rodríguez, J. C., \& Patiño-Guerra, M. C. (1996). Mujeres de Guadalajara y violencia doméstica: Resultados de un estudio piloto [Women of Guadalajara and domestic violence: Results from a pilot study]. Cadernos de Saúde Pública, 12, 405-409.

Rivera-Rivera, L., Lazcano-Ponce, E., Salmerón-Castro, J., Salazar-Martínez, E., Castro, R., \& Hernandez-Ávila, M. (2004). Prevalence and determinants of male partner violence against Mexican women: A population-based study. Salud Pública de México, 46, 1-10.

Schuler, S. R., Hashemi, S. M., \& Badal, S. H. (1998). Men's violence against women in rural Bangladesh: Undermined or exacerbated by microcredit programmes? Development in Practice, 8, 148-156. 
Schuler, S. R., Hashemi, S. M., Riley, A. P., \& Akhter, S. (1996). Credit programs, patriarchy, and men's violence against women in rural Bangladesh. Social Science \& Medicine, 43, 1729-1742.

Straus, M. A. (1979). Measuring intrafamily conflict and violence: The Conflict Tactics Scale. Journal of Marriage and the Family, 41, 75-88.

Straus, M. A. (2005). Women's violence toward men is a serious social problem. In D. R. Loseke, R. J. Gelles, \& M. M. Cavanaugh (Eds.), Current controversies on family violence (pp. 55-77). Thousand Oaks, CA: SAGE.

Straus, M. A., \& Gelles, R. J. (1986). Societal change and change in family violence from 1975 to 1985 as revealed by two national surveys. Journal of Marriage and the Family, 48, 465-479.

Straus, M. A., \& Gelles, R. J. (1990). Physical violence in American families: Risk factors and adaptations to violence in 8,145 families. New Brunswick, NJ: Transaction.

Tanha, M., Beck, C. J. A., Figueredo, A. J., \& Raghavan, C. (2010). Sex differences in intimate partner violence and the use of coercive control as a motivational factor for intimate partner violence. Journal of Interpersonal Violence, 25, 1836-1854.

Terrazas-Carrillo, E., \& McWhirter, P. T. (2012). Intimate partner violence and substance abuse: Contextualizing sociocultural complexities. In H. R. Cunningham \& W. F. Berry (Eds.), Handbook on the psychology of violence (pp. 29-51). New York, NY: Nova.

Tjaden, P., \& Thoennes, N. (2000a). Extent, nature, and consequences of intimate partner violence. Washington, DC: National Institute of Justice, U.S. Department of Justice.

Tjaden, P., \& Thoennes, N. (2000b). Prevalence and consequences of male-to-female and female-to-male intimate partner violence as measured by the National Violence Against Women Survey. Violence Against Women, 6, 142-161.

Vásquez Guerrero, D. A. (2009). Hypermasculinity, intimate partner violence, sexual aggression, social support, and child maltreatment risk in urban, heterosexual fathers taking parenting classes. Child Welfare, 88, 135-155.

Villarreal, A. (2007). Women's employment status, coercive control, and intimate partner violence in Mexico. Journal of Marriage and Family, 69, 418-434.

Vyas, S., \& Watt, C. (2009). How does economic empowerment affect women's risk of partner violence in low to middle income countries? A systematic review of published evidence. Journal of International Development, 21, 577-602.

Weidel, J. J., Provencio-Vásquez, E., Watson, S. D., \& González-Guarda, R. (2008). Cultural considerations for intimate partner violence and HIV risk in Hispanics. Journal of the Association of Nurses in AIDS Care, 19, 247-251.

World Health Organization. (2005). World Health Organization multi-country study on women's health and domestic violence against women: Summary report of initial results on prevalence, health outcomes and women's responses. Geneva, Switzerland: Author. 


\section{Author Biographies}

Elizabeth C. Terrazas-Carrillo, MA, is a doctoral student in the Counseling Psychology program at the University of Oklahoma, Norman. She is currently completing a predoctoral internship at the Texas State University Counseling Center and plans to earn her Doctor of Philosophy degree in August of 2014. She has accepted a position as Assistant Professor of Counseling Psychology in the Department of Psychology and Communications at Texas A\&M International University starting in August of 2014, where she hopes to continue expanding her research on interpersonal violence, women's employment, and international issues in counseling psychology.

Paula T. McWhirter, PhD, is Associate Professor in the Department of Educational Psychology at The University of Oklahoma, and currently serves as the Program Director of the Masters of Community Counseling Program. She teaches and investigates interpersonal violence interventions, international issues in counseling psychology and therapeutic factors within family/child counseling. She publishes extensively with her students and continues to be inspired by their creativity and broad array of counseling psychology research interests and contributions. 